\title{
Cultural Value Dimensions and Ethnicity within Kenya
}

\author{
Christopher K. Ketter ${ }^{1} \&$ Michael C. Arfsten ${ }^{1}$ \\ ${ }^{1}$ College of Business, Argosy University-Twin Cities, Eagan, MN, USA \\ Correspondence: Michael C. Arfsten, College of Business, Argosy University-Twin Cities, 1515 Central Parkway, \\ Eagan, MN 55121, USA. Tel: 1-612-986-9152. E-mail: marfsten@edmc.edu
}

Received: September 11, 2015

doi: 10.5539/ibr.v8n12p69
Accepted: October 16, $2015 \quad$ Online Published: November 25, 2015

URL: http://dx.doi.org/10.5539/ibr.v8n12p69

\begin{abstract}
The study compared the cultural values along the seven World Values Survey dimensions. Subjects were 811 males, age 18 to 35 , proportionately representing the 11 largest ethnic groups in Kenya. The study extended research in cultural differences between ethnic identities within a country, supplemental to cultural differences between countries. Significant differences are found between the Kenyan ethnic groups on the dimensions of masculinity, uncertainty avoidance, indulgence vs. restraint, and long-term orientation. Post-hoc analyses differentiated between individual ethnic groups on the cultural dimensions. Implications for management are presented to acknowledge ethnic differences in world orientation based on cultural dimension differences of ethnicities within Kenya.
\end{abstract}

Keywords: cultural differences, Kenya, ethnic groups, cultural dimensions, world values survey

\section{Introduction}

Research on cultural differences between societies continues to interest management scholars due to its implications on various facets of organizational management, such as leadership styles (House, 2014; Schein, 2010), entrepreneurship models (Mungai \& Ogot, 2012), and marketing approaches (Yoo, Donthu, \& Lenartowicz, 2011). Cultural research has been explored through examination of values at one of two levels: The individual-level (Rokeach, 1936 as reported in Schwartz, 1994) and the societal-level (Hofstede, 1980; House et al., 2004), while other researchers have undertaken cultural research by examining attitudes practices and tastes of participants (Dheer, Lenartowicz, Peterson, \& Petrescu, 2015). The individual-level approach measures goals deemed important by individuals as a proxy variable for espoused values (Schwartz, 1992), while the societal-level approach aggregates individual values to the societal level (Rokeach, 1936). Rokeach (1936) pioneered the individual-level stance by observing that an individual's value proposition forms the basis by which the individual's actions can be explained. He concluded that individuals within societies share similar values, hence belonging to the same culture. Hofstede (1980) synthesized past attempts by researchers to aggregate individual-level values to the societal level and identified four cultural dimensions that identified various societies: Individualism vs. collectivism, masculinity vs. femininity, uncertainty avoidance, and power distance. Further development of this concept led to the addition of three more dimensions: Long/Short Term Orientation, Indulgence vs. Self-Restraint, and Monumentalism Versus Self-Effacement (Hofstede, Hofstede, Minkov, \& Vinken, 2008) and numerous studies have over the years validated differences in various societies along these dimensions.

Hofstede's (1980) work remains the seminal basis for exploring societal culture at the aggregate level (Yoo, Donthu, \& Lenartowicz, 2011). However, a review of the extant literature reveals a gap in studies examining cultural differences from an ethnic perspective using Hofstede et al.'s (2008) scale. This is in spite of the existence of numerous societies with multi-ethnic populations globally and the fact that ethnicity remains a paradigm by which individuals in some societies primarily identify themselves with (Mungai \& Ogot, 2012). This study aims to contribute towards filling this gap.

The purpose of this study is; therefore, to explore cultural differences using Hofstede et al.'s (2008) measure of culture administered to participants from 11 ethnic communities in Kenya. A total of 823 participants comprising males aged 18-34 years old were sampled in 2014 as part of Ketter's (2014) study and data from this study will be used to explore any differences between ethnic cultures in Kenya.

Various theories inform this study. Tafjel's (1979) social identity theory posits that individuals within a group 
attempt to enhance their self-esteem by projecting a positive image about the in-group while minimizing the status of the out-group (McLeod, 2008). This leads to the projection of perceived shortcomings of the out-groups and to an emphasis of what is perceived as the superior aspects of the in-group (McLeod, 2008). Turner and Oakes's (1986) self-categorization theory extended Tafjel's (1979) social identity theory by surmising that the "in-group, out-group" perception held by individuals is driven by psychological processes that dispossesses the individual of his/her uniqueness in exchange for shared features within the in-group, consequently compelling one to align behavior to the behaviors of his/her in-group (Hogg \& Terry, 2000). Wyer (2010) noted that individuals are more likely to identify with a certain practice if the practice is salient within the in-group and that individuals are more likely to align themselves with groups that ascribe to similar values as the individual.

Functional theory has been employed as an explanation of how environmental factors shape societal norms. Environmental factors influence the kind of activities that societal members engage in and the traditions practiced within a certain geographic region, leading to formation of distinct cultural groups within geographic regions (Dheer, Lenartowicz, Peterson, \& Petrescu, 2015). The social identity, social categorization, and functional theories capture the essence by which distinct cultures evolve either at a societal (national), sub-cultural, or organizational level (Yoo, Donthu, \& Lenartowicz, 2011).

Outcomes of this study have implications for various stakeholders: multinational organizations, government agencies charged with formulating economic growth policies, and on organizational practices to be utilized by multinationals as they venture into culturally diverse societies. Dheer, Lenartowicz, Peterson, and Petrescu (2015) posited that organizations can utilize similar practices such as "employee selection, training procedures, compensation, performance appraisals, organizational structure, hierarchical relations, ethical decision making, (and) competitive versus cooperative strategies" (p. 345) in societies that share similar cultural perspectives. This study will aid organizations by portraying the homogeneity or heterogeneity of Kenyan ethnic communities; thus, enabling corporations to identify the most effective management approaches to utilize. Promotion of entrepreneurship remains a key strategy of the Kenyan government in its goal of promoting economic growth (Kiraka, Kobia, \& Katwalo, 2013). Holden and Glisby (2010) surmised that organizations valuing diverse cultural perspectives as reservoirs of knowledge have a competitive knowledge advantage over other organizations. A community's orientation on the individualism/collectivism dimension influences the appropriate funding model, with members of individualistic societies preferring individual-based funding models while those from collectivist cultures preferring group based models (Kodongo \& Kendi, 2013).

Outcomes of this study will portray differences between communities; thus, enabling governmental stakeholders to proffer an appropriate funding model to each community based on their orientation. National and multinational organizations intending to extend products and services to various parts of Kenya will benefit from this study by gaining a better understanding of a preferred marketing approach. According to Zúñiga and Torres (2014), collectivist societies respond positively to low-construal messages, while individualistic societies respond positively to high construal messages. Marketing strategies must be tailored to a societies' preferred level of messaging if the product or service offering is to be effective (Zúñiga \& Torres, 2014). This study will aid corporations identify communities' preferred messaging level based on each society's individualism/collectivist score, consequently ensuring effective formulation of marketing strategies.

\subsection{Research Questions}

1) Are there cultural differences between Kenyan ethnicities as measured by Hofstede et al.'s (2008) seven cultural dimensions scales?

2) Do Hofstede et al.'s (2008) cultural dimensions discriminate among ethnicity within Kenyan society?

\section{Literature Review}

Dheer, Lenartowicz, Peterson, and Petrescu (2015) clustered the U.S.A. and Canadian populations into nine cultural groups and then validated the existence of these cultural groups using Lenartowicz and Roth's (1999) intra-regional cultural assessment framework. Dheer et al. (2015) used Inglehart (1997) and Inglehart and Baker's (2000) three values and three attitudes commonly used to measure cultural perspectives to measure culture at the individual level. The three values are "traditional versus secular-rational, survival versus self-expression, and postmaterialism" (Dheer et al., 2015, p. 363), while the three attitude measures are attitudes toward behavior considered unethical, attitude towards trust in general, and attitude towards the role of women. Nine questions were used to measure culture from an attitude perspective; four questions were used to measure attitude toward unethical behavior; three questions were used to measure general trust; and two questions were used to assess attitude towards women. The twelve item post-materialism scale was used to measure cultural value dimensions. Archival data from the World Values Survey (WVS) database was used in the study. Dheer et 
al. (2015) found that there were nine distinct regional sub-cultures within the United States and Canada, and that individual-level differences supported the regional sub-cultures.

Minkov and Hofstede (2011) investigated whether national cultures can be discerned when in-country regions of several countries and four regions of the world are clustered. Using the World Values Survey data, Minkov and Hofstede (2011) grouped nations into categories based on geographic proximity and then identified several regions within each category as units of analysis. The four categories were East and South East Asia, Sub-Saharan Africa, Latin America, and Anglo-Speaking countries. Minkov and Hofstede (2011) then used the Euclidian distance and the Pearson Methods to analyze six personal values, ten children values, and ten Schwartz (1994) values as proxy variables for culture and concluded that $88.1 \%$ of East and South East Asian regions, $91 \%$ of regions in Sub-Saharan Africa, 97\% of Latin American regions, and 83\% of Anglo regions clustered together with a high proportion of regions within each country clustering together. Minkov and Hofstede (2011) concluded that the concept of national culture remains relevant based on these outcomes.

Hofstede, Garibaldi de Hilal, Malvezzi, Tanure, and Vinken (2010) explored whether regional scores of participants from Brazil's 27 states reflected Brazil's national scores from the original Hofstede study. They further investigated if clustering could be observed among some states. Using data collected in three past studies (Caetano, 2003; Garibaldi, 2002; Tanure, 2002), Hofstede et al. (2010) employed Procrustean factor analysis to force the data into one data set. Outcomes of their first analysis revealed that there was no consistency between Brazil's national scores and the regional scores obtained from their analysis, while outcomes of the second analysis indicated that differences rooted in ethnicity existed between participants with Afro and Indian cultural roots on masculinity with participants from Indian decent scoring higher (Hofstede, Garibaldi, Malvezzi, Tanure, \& Vinken, 2010).

Peterson and Fanimokun (2008) as reported in Minkov and Hofstede (2011) explored whether Nigerian ethnic communities that live in close proximity share similar values and concluded that there was significant diversity between the communities in spite of their geographic proximity.

\section{Method}

\subsection{Instrumentation}

The Values Survey Module 2008 (VSM08), a 28 item survey with five additional demographic questions, is used to survey participants from the 11 communities. The independent variable is ethnic group, and the dependent variables are the seven value dimensions. Items are rated by participants on a Likert scare from 1 to 5 with scoring on each dimension being a weighted formula of four items. The seven dimensions and brief definitions are (Hofstede, Hofstede, Minkov, \& Vinken, 2008):

Power distance (PDI): A society that accepts that power is distributed unequally.

Individualism (IDV): A society with loose ties between individuals; the opposite of a collectivist society.

Masculinity (MAS): A society with clearly distinct gender roles; the opposite of femininity.

Uncertainty avoidance (UAI): A society wherein members strive to avoid the ambiguous, unstructured, uncertain or unknown.

Long term orientation (LTO): A society promoting long-term or future rewards and orientation; the opposite of short-term orientation.

Indulgence vs. restraint (IVR): A society which accepts free gratification vs. a society that controls gratification.

Monumentalism (MON): A society that is proud and less flexible; the opposite of a society favoring humility and flexibility.

\subsection{Sample}

The participants were selected from 11 ethnically homogeneous counties in Kenya as depicted in Figure 1 and Table 1. Ethnic population data was used to identify counties, and largest city within the county, with the largest target population. The 11 target ethnic groups were: Kalenjin, Kamba, Kikuyu, Kisii, Luhya, Luo, Masai, Meru, Mijikenda, Somali, and Turkana. Total sample size was estimated based on a .80 power and a medium effect size. Ethnic group samples were estimated proportionately from ethnic group population. The survey was administered by research assistants in the largest city within each of the eleven ethnic community locations. Subjects were asked to participate in a research study, and if they agreed they were given a consent form and the survey to complete. Of the 823 initial participants, complete data was received from 811 participants and used in the analysis. 


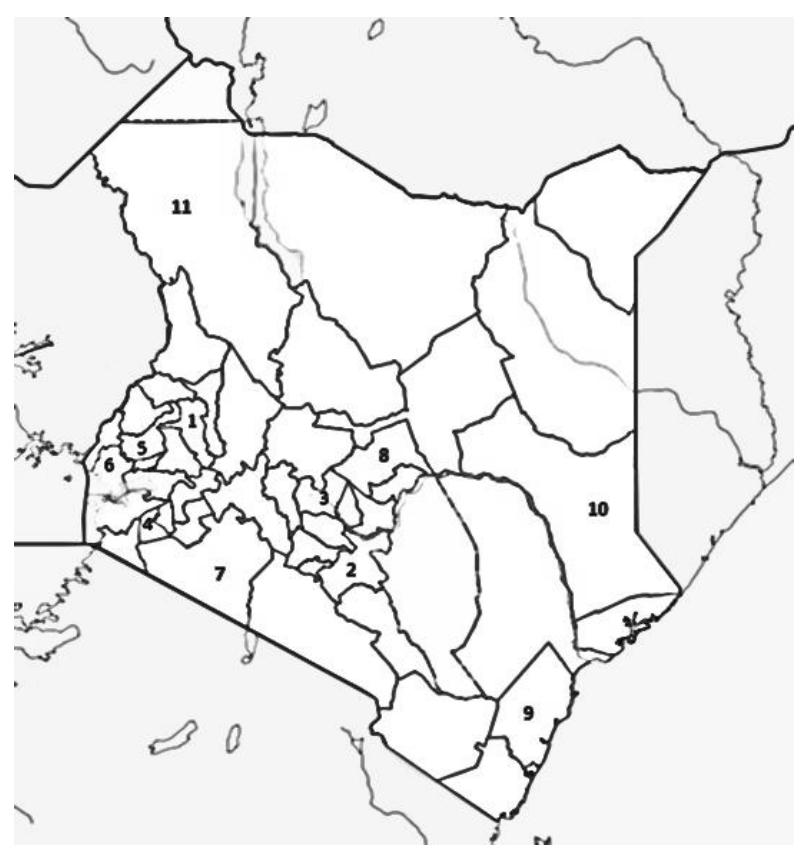

Figure 1. Location of ethnic communities sampled as described in Table 1

Table 1. Ethnic population distribution, sample size, and source

\begin{tabular}{clcccl}
\hline Map Code & Ethnicity & Percent of Population & Sample & Percent of Sample & Sample Town, County \\
\hline 1 & Kalenjin & 14.2 & 110 & 13.6 & Eldoret, Uasin Gishu County \\
2 & Kamba & 11.2 & 92 & 11.3 & Machakos, Machakos county \\
3 & Kikuyu & 19.0 & 153 & 18.9 & Nyeri, Nyeri County \\
4 & Kisii & 6.3 & 52 & 6.4 & Kisii, Kisii County \\
5 & Luhya & 15.3 & 126 & 15.5 & Kakamega, Kakamega County \\
6 & Luo & 11.6 & 95 & 11.7 & Siaya, Siaya County \\
7 & Masai & 2.4 & 21 & 2.6 & Narok, Narok County \\
8 & Meru & 4.8 & 39 & 4.8 & Meru, Meru County \\
9 & Mijikenda & 5.6 & 44 & 5.4 & Kilifi, Kilifi County \\
10 & Somali & 6.8 & 56 & 6.9 & Garissa, Garissa County \\
11 & Turkana & 2.8 & 23 & 2.8 & Lodwar, Turkana County \\
\hline
\end{tabular}

\subsection{Alpha Level}

The alpha level for rejection of the null hypotheses was set at a conservative value of .001. The Games-Howell procedure was used to control for multiple post hoc tests with unequal variances (Kromrey \& La Rocca, 1995).

\section{Analysis}

Prior to analysis, six subjects were eliminated due to missing values and seven subjects were eliminated due to extreme outliers. Missing values and extreme outliers were deleted (> $4 \mathrm{SD}$ ), which reduced the sample size to 811 participants. Table 2 presents the demographic characteristics of the sample. 
Table 2. Demographic characteristics of the sample

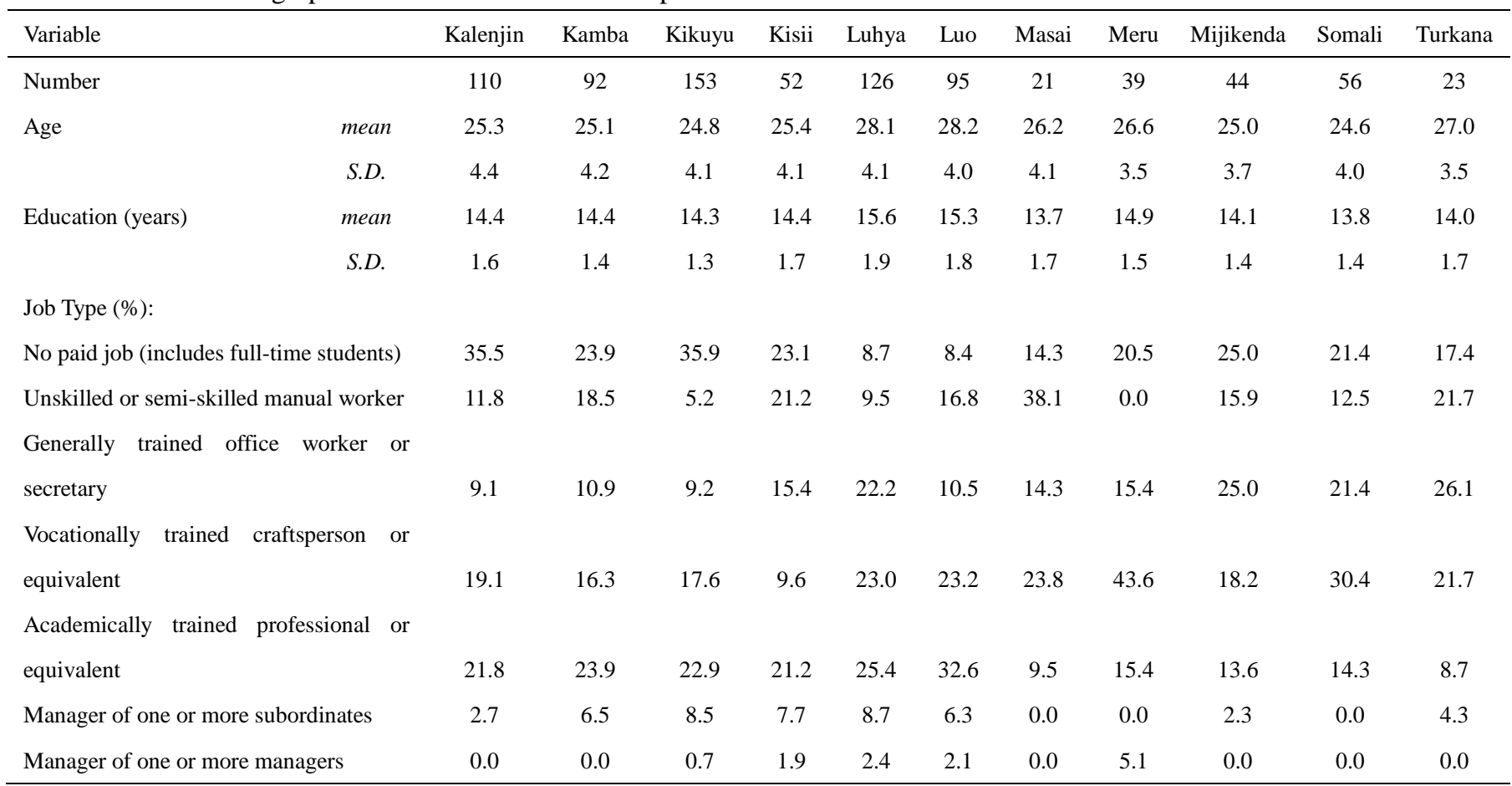

Table 3 presents the correlations among the demographic variables and VSM dimensions. Other than the correlation between age and education, the correlations are relatively low. This would be expected, as the VSM dimensions are posited to be independent of each other.

Table 3. Descriptive statistics and correlations

\begin{tabular}{|c|c|c|c|c|c|c|c|c|c|c|c|}
\hline & Mean & $\mathrm{SD}$ & Age & Education & PDI & IDV & MAS & UAI & LTO & IVR & MON \\
\hline Age & 26.02 & 4.28 & 1.00 & $.651^{* *}$ & -.004 & -.050 & $.097^{* *}$ & $.106^{* *}$ & $.157^{* * *}$ & $-.135^{* * *}$ & $-.075^{*}$ \\
\hline Education & 14.60 & 1.68 & $.651^{* *}$ & 1.00 & -.045 & -.011 & $.117^{* *}$ & $.090^{*}$ & $.190^{* *}$ & $-.110^{* *}$ & -.017 \\
\hline PDI & 50.00 & 45.57 & -.004 & -.045 & 1.00 & $.088^{*}$ & $-.142^{* *}$ & $-.088^{*}$ & $-.112^{* *}$ & .047 & .010 \\
\hline IDV & 50.00 & 46.10 & -.050 & -.011 & $.088^{*}$ & 1.00 & .013 & -.014 & .013 & .057 & -.056 \\
\hline MAS & 50.00 & 46.56 & $.097^{* *}$ & $.117^{* *}$ & $-.142^{* *}$ & .013 & 1.00 & .044 & $.076^{*}$ & $-.085^{*}$ & -.008 \\
\hline UAI & 50.00 & 52.20 & $.106^{* *}$ & $.090^{*}$ & $-.088^{*}$ & -.014 & .044 & 1.00 & $.197^{* *}$ & $-.146^{* *}$ & $-.154^{* *}$ \\
\hline LTO & 50.00 & 62.96 & $.157^{* *}$ & $.190^{* * *}$ & $-.112^{* *}$ & .013 & $.076^{*}$ & $.197^{* *}$ & 1.00 & $-.138^{* * *}$ & .004 \\
\hline IVR & 50.00 & 58.84 & $-.135^{* *}$ & $-.110^{* *}$ & .047 & .057 & $-.085^{*}$ & $-.146^{* *}$ & $-.138^{* *}$ & 1.00 & $.131^{* *}$ \\
\hline MON & 50.00 & 45.23 & $-.075^{*}$ & -.017 & .010 & -.056 & -.008 & $-.154^{* *}$ & .004 & $.131^{* * *}$ & 1.00 \\
\hline
\end{tabular}

Notes. *. Correlation is significant at the 0.05 level (2-tailed).

**. Correlation is significant at the 0.01 level (2-tailed).

A one-way multivariate analysis of variance (MANOVA) was conducted to determine ethnic group differences on the seven VSM dimensions. MANOVA results indicated significant differences among the ethnic groups on the dependent variables, Pillai's Trace $V=.456, F(70,5600)=5.574, p<.001$, partial $\eta^{2}=.065$. Table 4 presents the means and standard deviations for each ethnic group on each VSM dimension. 
Table 4. Descriptive statistics for VSM dimensions by ethnicity

\begin{tabular}{|c|c|c|c|c|c|c|c|c|c|c|c|c|}
\hline \multirow{2}{*}{ Dimension } & & Kalenjin & Kamba & Kikuyu & Kisii & Luhya & Luo & Masai & Meru & Mijikenda & Somali & Turkana \\
\hline & $n$ & 110 & 92 & 153 & 52 & 126 & 95 & 21 & 39 & 44 & 56 & 23 \\
\hline \multirow{2}{*}{ PDI } & mean & 49.6 & 51.6 & 60.8 & 53.1 & 44.2 & 42.7 & 49.5 & 41.2 & 55.3 & 38.9 & 61.0 \\
\hline & S.D. & 47.5 & 50.1 & 44.0 & 61.9 & 35.1 & 38.0 & 49.8 & 36.2 & 41.2 & 55.6 & 45.1 \\
\hline \multirow{2}{*}{ IDV } & mean & 53.4 & 50.5 & 47.2 & 46.2 & 54.2 & 43.5 & 54.2 & 63.4 & 62.8 & 32.7 & 53.9 \\
\hline & S.D. & 50.1 & 42.9 & 49.0 & 57.2 & 36.9 & 36.4 & 51.8 & 43.6 & 53.3 & 46.2 & 45.9 \\
\hline \multirow{2}{*}{ MAS } & mean & 55.3 & 64.2 & 28.9 & 38.7 & 62.5 & 56.6 & 27.2 & 64.2 & 59.6 & 35.1 & 52.8 \\
\hline & S.D. & 56.7 & 49.2 & 41.4 & 40.6 & 36.2 & 35.3 & 42.7 & 49.8 & 51.5 & 42.3 & 52.4 \\
\hline \multirow{2}{*}{ UAI } & mean & 49.8 & 42.9 & 27.5 & 35.3 & 77.8 & 71.2 & 60.4 & 49.7 & 41.0 & 52.0 & 25.6 \\
\hline & S.D. & 50.5 & 47.8 & 44.7 & 47.0 & 50.5 & 50.5 & 60.1 & 53.0 & 45.5 & 63.4 & 41.8 \\
\hline \multirow{2}{*}{ LTO } & mean & 38.6 & 15.0 & 28.1 & 44.0 & 98.7 & 86.9 & 58.1 & 71.3 & 19.9 & 32.8 & 40.7 \\
\hline & S.D. & 66.6 & 58.6 & 56.0 & 57.8 & 40.5 & 51.0 & 53.7 & 50.3 & 67.4 & 57.5 & 60.2 \\
\hline \multirow{2}{*}{ IVR } & mean & 55.1 & 64.3 & 62.5 & 71.7 & 31.8 & 36.6 & 34.7 & 19.4 & 57.9 & 44.0 & 56.2 \\
\hline & S.D. & 65.1 & 63.4 & 53.0 & 55.5 & 42.5 & 45.6 & 58.7 & 51.1 & 70.0 & 82.0 & 45.5 \\
\hline \multirow{2}{*}{ MON } & mean & 51.7 & 54.2 & 58.0 & 62.8 & 44.5 & 40.9 & 31.1 & 48.6 & 49.6 & 48.2 & 35.6 \\
\hline & S.D. & 52.5 & 34.4 & 41.3 & 51.8 & 35.0 & 38.1 & 60.5 & 46.6 & 39.6 & 69.5 & 37.1 \\
\hline
\end{tabular}

The Levene Test of Homogeneity of Variances indicated that the dependent variables are not homogeneously distributed among ethnicities. Therefore, analysis of variance (ANOVA) with Brown-Forsythe $F$ was conducted on each dependent variable as a follow-up test to MANOVA. Ethnic differences were significant for the dimension of Masculinity (MAS), Brown-Forsythe $F(10,800)=7.793, p<.001$, partial $\eta^{2}=.089$. Table 5 also presents the Games-Howell post hoc analysis indicating that Kalenjin differs from Kikuyu; Kamba differs from Kikuyu and Somali; Kikuyu differs from Luhya, Luo, and Mero; and Luhya differs from Somali on the Masculinity dimension.

Ethnic differences were significant for the dimension of Uncertainty Avoidance (UAI), Brown-Forsythe $F$ (10, $423.761)=9.854, p<.001$, partial $\eta^{2}=.115$. Table 5 presents the Games-Howell post hoc analysis indicating that Kalenjin differs from Luhya; Kamba differs from Luhya and Luo; Kikuyu differs from Luhya and Luo; Kisii differs from Luhya and Luo; Luhya differs from Mijikenda; and Turkana and Luo differs from Turkana on the Uncertainty Avoidance dimension.

Ethnic differences were significant for the dimension of Long-Term Orientation (LTO), Brown-Forsythe $F$ (10, $463.805)=21.876, p<.001$, partial $\eta^{2}=.220$. Table 5 shows the Games-Howell post hoc analysis indicated that Kalenjin differs from Luhya and Luo; Kamba differs from Luhya, Luo, and Meru; Kikuyu differs from Luhya, Luo, and Meru; Kisii differs from Luhya and Luo; Luhya differs from Mijikenda, Somali, and Turkana; Luo differs from Mijikenda and Somali; and Meru differs from Mijikenda on the Long-term Orientation dimension.

Ethnic differences were significant for the dimension of Indulgence vs. Restraint (IVR), Brown-Forsythe $F$ (10, $451.553)=5.104, p<.001$, partial $\eta^{2}=.063$. Table 5 presents the Games-Howell post hoc analysis indicated that Kamba differs from Luhya and Meru; Kikuyu differs from Luhya, Luo, and Meru; Kisii differs from Luhya, Luo, and Meru on the Indulgence vs. Restraint dimension.

Table 5. Results of the MANOVA and Brown-Forsythe ANOVA on VSM dimensions

\begin{tabular}{lcclc}
\hline & & & Brown-Forsythe F ANOVA & $\underline{\text { F }}$ \\
\hline MANOVA & & & Personal Distance & 1.929 \\
Pillai's Trace & $\underline{\text { Value }}$ & $\underline{\mathrm{F}}$ & Individualism & 1.846 \\
Wilks' Lambda & .456 & $5.574^{*}$ & Masculinity & $7.405^{*}$ \\
Hotelling's Trace & .596 & $6.140^{*}$ & Uncertainty Avoidance & $9.854^{*}$ \\
Roy's Largest Root & .593 & $6.715^{*}$ & Long Term Orientation & $21.876^{*}$ \\
\hline
\end{tabular}




\begin{tabular}{|c|c|c|c|}
\hline & & Monumentalism & 1.970 \\
\hline \multicolumn{4}{|c|}{ Games-Howell Multiple Comparisons } \\
\hline Ethnic Group Pair & Mean Difference & Ethnic Group Pair & Mean Difference \\
\hline Masculinity: & & Long Term Orientation: & \\
\hline Kamba-Kikuyu & $35.29 *$ & Luhya-Kalenjin & $60.14 *$ \\
\hline Luhya-Kikuyu & $33.58 *$ & Luhya-Kamba & $83.65^{*}$ \\
\hline Luo-Kikuyu & $27.76^{*}$ & Luhya-Kikuyu & $70.62 *$ \\
\hline Uncertainty Avoidance: & & Luhya-Kisii & $54.73^{*}$ \\
\hline Luhya-Kamba & $34.88 *$ & Luhya-Mijikenda & $78.76^{*}$ \\
\hline Luhya-Kikuyu & $50.31 *$ & Luhyu-Somali & $65.87 *$ \\
\hline Luhya-Kisii & $42.50^{*}$ & Luo-Kalenjin & $48.33^{*}$ \\
\hline Luhya-Turkana & $52.22 *$ & Luo-Kamba & $71.85^{*}$ \\
\hline Luo-Kikuyu & $43.68 *$ & Luo-Kikuyu & $58.82 *$ \\
\hline Indulgence vs. Restraint: & & Luo-Mijikenda & $66.96^{*}$ \\
\hline \multirow[t]{2}{*}{ Kikuyu-Luhya } & $30.74 *$ & Luo-Somali & $54.07 *$ \\
\hline & & Meru-Kamba & $56.21 *$ \\
\hline
\end{tabular}

Note. $* \mathrm{p}<.001$

A discriminant analysis was conducted to determine whether the seven VSM dimensions-PDI, IDV, MAS, UAI, LTO, IVR, and MON-could differentiate ethnicity among Kenyans. Table 6 shows that two functions were generated and were significant. The first function, $\Lambda=.596, \mathrm{X}^{2}(70, N=811)=414.042, p<.001$, accounted for $72.1 \%$ of function variance. The second function, $\Lambda=.852, \mathrm{X}^{2}(54, N=811)=128.667, p<.001$, accounted for $15.0 \%$ of function variance. Combined the two functions accounted for $87.2 \%$ of function variance. Standardized function coefficients and correlation coefficients (see Table 6) indicate that the dimensions of LTO, UAI, and MAS were most associated with the two functions. Based on these results, the first function was labeled Long-term/certainty and the second Masculinity. Cross-validation classification results indicated $21.1 \%$ accuracy for the total sample.

Table 6. Correlation coefficients and standardized function coefficients

\begin{tabular}{lcccc}
\hline & \multicolumn{2}{c}{ Correlation Coefficients with Discriminant Function } & \multicolumn{2}{c}{ Standardized Function Coefficients } \\
\hline LTO & Function 1 & Function 2 & Function 1 & Function 2 \\
MAS & .788 & -.351 & .742 & -.385 \\
IDV & .268 & .855 & .234 & .876 \\
IVR & .041 & .295 & .063 & .307 \\
MON & -.349 & .063 & -.252 & .087 \\
UAI & -.180 & -.012 & -.145 & .031 \\
PDI & .519 & .118 & .427 & .177 \\
\hline
\end{tabular}

The means of the discriminant functions in Table 7 show a separation of ethnicities consistent with these results in Figure 2.

Table 7. Functions at group centroids

\begin{tabular}{lcc}
\hline & \multicolumn{2}{c}{ Function } \\
\hline Ethnic Group & Long term/Certainty & Masculinity \\
\hline Kikuyu & -.700 & -.338 \\
Kalenjin & -.148 & .214 \\
Kamba & -.529 & .520 \\
Kisii & -.414 & -.217 \\
Luhya & 1.065 & .006 \\
Luo & .799 & -.118 \\
Masai & .213 & -.473 \\
Meru & .527 & .174 \\
\hline
\end{tabular}




\begin{tabular}{lcc}
\hline Mijikenda & -.451 & .461 \\
Somali & -.260 & -.292 \\
Turkana & -.315 & .056 \\
\hline
\end{tabular}

Note. Unstandardized canonical discriminant functions evaluated at group means.

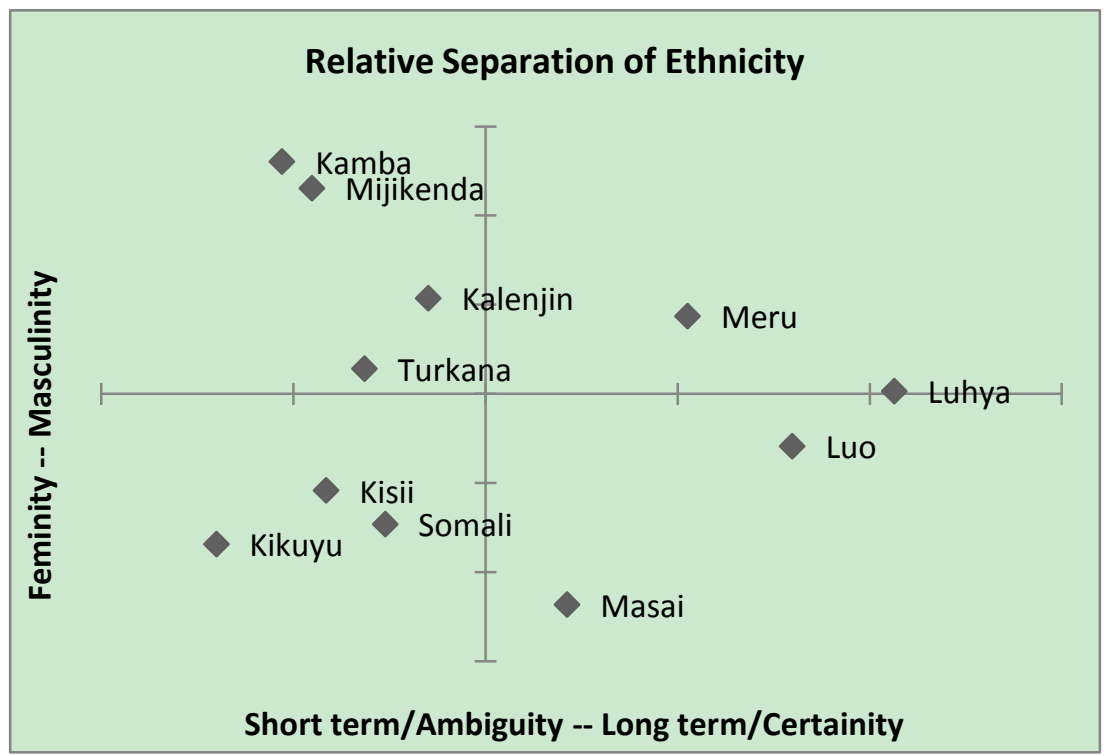

Figure 2. Ethnic group separation on two significant discriminant group functions

\section{Discussion, Implications, and Conclusion}

\subsection{Discussion}

Tailoring products and services to diverse customer groups has become more challenging as national barriers become less significant in the conduct of business. This phenomenon is occasioned by globalization that has seen national trade barriers dismantled in preference of free trade zones between countries. Consequently, organizations are faced with the challenges of understanding new markets as well as new customer bases that are different from their traditional clientele. This challenge assumes greater significance when organizations expand into countries with diverse populations that have distinct cultural paradigms. Multinational organizations either have to embrace a differentiation or an integrative strategy to be effective while expanding into new frontiers (Muscalu, 2014). This entails either maintaining an organization's home country cultural strategy in the new environment or adapting to the new environment's preferred management cultural approach. This article analyzes the diversity of eleven Kenyan ethnic communities using Hofstede's (1981) framework as a way of providing a synoptic view of Kenya's cultural diversity.

The first research question explored whether cultural differences exists between Kenyan ethnic communities when measured using Hofstede et al.'s (2008) seven cultural dimensions. A total of 825 participants from eleven ethnic communities were sampled, with 811 participants being considered to have adequately responded to the modified Value Survey Module's 33 questions being used in the analyses. A MANOVA analysis revealed that differences existed between the ethnic communities on the cultural dimensions, Pillai's Trace $V=.456, F$ (70, $5600)=5.574, p<.001$, partial $\eta^{2}=.065$. Lack of homogeneity of variance between the ethnic communities as revealed by Levene's test necessitated follow up ANOVA analyses on each dependent variable, with outcomes revealing statistically significant differences in Masculinity, Uncertainty Avoidance, Long/Short-term Orientation, and Indulgence versus Restraint. Post-hoc analyses using Games-Howell's test revealed the following: A statistically significant difference on Masculinity exists between Kalenjins and Kikuyus; between Kambas and Kikuyus; between Kambas and Somali; between Kikuyus and the following three ethnicities: Luhya, Luo, and Mero; and between Luhyas and Somalis. Games-Howell's test revealed the following differences on Uncertainty Avoidance: Kalenjins differ from Luhyas; Kamba differ from Luhyas and Luos; Kikuyus differ from Luhyas and Luos; Kisiis differ from Luhyas and Luos; Luhyas differ from Mijikendas and Turkanas and Luos differ from Turkanas. A difference on Long/Short Term Orientation were observed between the following ethnic communities: Kalenjin differs from Luhya and Luo; Kamba differs from Luhya, Luo, and Meru; Kikuyu differs 
from Luhya, Luo, and Meru; Kisii differs from Luhya and Luo; Luhya differs from Mijikenda, Somali, and Turkana; Luo differs from Mijikenda and Somali; and Meru differs from Mijikenda. A difference was also observed between the Kikuyus and the Luhyas on Indulgence versus self-restraint.

The second research question explored whether Hofstede et al.'s (2008) seven cultural dimensions can discriminant between Kenyan ethnicities; and a discriminant analysis generated two functions that were significant. The first function accounted for $72.1 \%$ of the function variance while the second accounted for an additional $15 \%$ of the variance with standardized function coefficients revealing that three dimensions, LTO, MAS, and UAI were mostly associated with the two functions.

\subsection{Implications}

Outcomes of this study have implications on national and international organizations conducting or intending to conduct businesses in Kenya. Observed statistically significant differences in LTO, MAS, and UAI call for the application of appropriate management, marketing, and funding models for ethnic communities based on their cultural orientation.

A community's orientation toward uncertainty avoidance (UAI) affects the preferred leadership style to be adopted; with individuals from high uncertainty cultures being less tolerant of charismatic leaders (Duncan, Green, and Herrera (2012) as well as of leaders with strong personalities (Hofstede, 1980). This calls for the adoption of different leadership styles in Kenyan counties based on the prevailing uncertainty avoidance dimension in each county. For instance, a charismatic leadership approach may align well in Uasin Gishu County inhabited by the Kalenjins with a mean UAI score of 49.8 while a hierarchical leadership approach may be appropriate in Kakamega County inhabited by the Luhya community with a mean UAI score of 77.8. Organizations may also increase success by employing leaders with strong personalities in low UAI counties such as in Kisii County with a mean score of 35.3 while employing leaders with high levels of tolerance in high UAI counties such as Kisumu with a mean score of 71.2. Duncan, Green, and Herrera (2012) notes that a hierarchical leadership style is appropriate in high UAI cultures as employees in organizations portraying a high uncertainty orientation prefer leaders who take responsibility for the organization's successes as well as failures. Decision-making in high UAI cultures should be top-down with the organization's leaders making decisions to be implemented by subordinates (Duncan, Green, \& Herrera, 2012).

Long-term oriented (LTO) societies place less emphasis on immediate gratification and prefer to save towards future purchases, while short-term oriented societies are more inclined to make purchases on credit (Bearden, Money, \& Nevins, 2006). Marketing organizations should tailor their approaches based on this preference in Kenyan counties; with more short-term oriented marketing approaches being employed in counties such as Nyeri County inhabited by Kikuyus with a mean LTO score of 28.1 and Kamba with a mean score of 15 while long-term oriented approaches should be implemented in counties inhabited by communities with long-term orientation such as in Meru County with a mean score of 71.3 and in Luhya inhabited counties with a mean score of 98.7. Communities scoring low on LTO are more likely to purchase on credit while communities scoring high on this dimension prefer cash purchases, and organizations should be cognizant of these differences while designing their marketing strategies.

Societies with high masculinity (MAS) scores are characterized by a clear delineation of male and female responsibilities; with men undertaking more of the outdoors activities while females focus on the household responsibilities (Hofstede, Hofstede, Minkov, \& Vinken, 2008). In contrast, responsibilities overlap in low masculinity cultures between the genders. Furthermore, men in societies with high MAS scores are more focused on material success and are expected to be assertive and tough, while females are more focused on quality of life and are expected to be modest and tender (Hofstede, Hofstede, Minkov, \& Vinken, 2008). These differences affect organizational cultures with more women in leadership roles in low MAS oriented cultures compared to high masculinity oriented cultures (Ohllsson \& Ondelj, 2006). Furthermore, the assertive trait of high masculinity societies lends itself to high levels of competition among employees; hence, preference for a more individualistic approach to tasks compared to a preference for a collectivist approach in low MAS oriented societies. Additionally, high masculine oriented societies prefer leaders that are aggressive and resolute with a high level of self-assurance (Ohllsson \& Ondelj, 2006). More individual based task approaches may; thus, be more aligned with the Mijikenda and Luhya communities with high MAS scores while group-based approaches may work well with the Masai with a low mean MAS scores of 27.2.

The discriminant analysis indicates that in the longer term orientation with more certainty, the MAS differences are less important as indicated by the Luhya (and to a lesser degree, the Meru and Luo) scores on masculinity. In the shorter term orientation and more ambiguous situations, masculinity can differentiate between ethnicities. If 
the orientation is towards the future and the orientation is towards certainty, then the masculinity orientation preference of competition or cooperation is less important when the future goals is identified with uncertainty. In the shorter term with an uncertain orientation, the ethnicities do differ on the MAS dimension between competition and cooperation. Kikuyu, Kisii, and Somali prefer cooperation, whereas Kamba, Mijikenda, and Kalenjin prefer a more competitive orientation. Awareness of these preferences may help managers in Kenya understand and accommodate orientation preferences depending on the uncertainty and time horizon of the decision or situation to be addressed.

\subsection{Conclusions}

This study examined whether there are cultural differences between eleven ethnic communities in Kenya concluding that differences exist in the cultural dimensions of long/short term orientation, uncertainty avoidance, indulgence versus restraint, and masculinity between some ethnic communities. This led to recommendations for an alignment of organizational management strategies with recommended effective strategies in extant literature based on communities' orientation. This study is delimited in that no effort was made to ascertain why the observed cultural differences exist and we leave it to future researchers to attempt to explore this question.

\section{References}

Bearden, W. O., Money, R. B., \& Nevins, J. L. (2006). A measure of long-term orientation: Development and validation. Academy of Marketing Science Journal, 34(3), 456-467. http://dx.doi.org/10.1177/0092070306286706

Dheer, R., Lenartowicz, T., Peterson, M., \& Petrescu, M. (2015). Cultural regions of Canada and the United States: Implications for international management research. International Journal of Cross Cultural Management. http://dx.doi.org/10.1177/1470595814543706

Duncan, P., Green, M. T., \& Herrera, R. (2012). Culture predicting leadership. Business Studies Journal, 471-484.

Hofstede, G. (1980). Culture's consequences: International differences in work-related values. Beverly Hills, CA: Sage.

Hofstede, G., Garibaldi de Hilal, A. V., Malvezzi, S., Tanure, B., \& Vinken, H. (2010). Comparing regional cultures within a country: Lessons from Brazil. Journal of Cross-Cultural Psychology, 41(3), 336-352. http://dx.doi.org/10.1177/0022022109359696

Hofstede, G., Hofstede, G. J., Minkov, M., \& Vinken, H. (2008). Values Survey Module 2008 manual. Retrieved from http://www.geerthofstede.nl/vsm-08

Hogg, M. A., \& Terry, D. J. (2000). Social identity and self-categorization processes in organizational contexts. The Academy of Management Review, 25(1), 121-140. http://dx.doi.org/10.2307/259266

Holden, N. J., \& Glisby, M. (2010). Researching and writing about tacit knowledge: Some observations on a case-based book on an elusive phenomenon. European Journal of Cross-Cultural Competence and Management, 1, 303-314. http://dx.doi.org/10.1504/EJCCM.2010.037639

House, R. J. (2014). Strategic leadership across cultures: The GLOBE study of CEO leadership behavior and effectiveness in 24 countries. Thousand Oaks, California: SAGE Publications, Inc.

Ketter, C. (2014). An exploration of the influence of cultural dimensions on entrepreneurial self-efficacy of young males from six selected ethnic communities in Kenya (Doctoral dissertation).

Kodongo, O., \& Kendi, L. G. (2013). Individual lending versus group lending: An evaluation with Kenya's microfinance data. Review of Development Finance, 3(2), 99-108. http://dx.doi.org/10.1016/j.rdf.2013.05.001

Kromrey, J. D., \& La Rocca, M. A. (1995). Power and type I error rates of new pairwise multiple comparison procedures under heterogeneous variances. The Journal of Experimental Education, 63(4), 343-362. http://dx.doi.org/10.1080/00220973.1995.9943469

Lenartowicz, T., Dheer, R., \& Peterson, M. (2015). Mapping India's regional sub-cultures: Implications for international management. Journal of International Business Studies, 46(1), 444-467. http://dx.doi.org/10.1057/jibs.2014.70

McLeod, S. (2008). Social Identity Theory. Retrieved from http://www.simplypsychology.org/social-identity-theory.html 
Minkov, M., \& Hofstede, G. (2011). Is national culture a meaningful concept? Cultural values delineate homogenous national clusters of in-country Regions. Cross-Cultural Research, 46(133). http://dx.doi.org/10.1177/1069397111427262

Mungai, E. N., \& Ogot, M. (2012). Gender, culture and entrepreneurship in Kenya. International Business Research, 5(5), 175-183. http://dx.doi.org/10.5539/ibr.v5n5p175

Muscalu, E. (2014). Organizational culture in the age of globalization. Buletin Stiinjific, 2(38). Retrieved from http://www.armyacademy.ro/buletin/bul2_2014/MUSCALU.pdf

Ohllsson, C., \& Ondelj, S. (2006). What happens with company culture when high and low masculine cultures merge? A case study of the joint venture Sony Ericsson (Order No. 685, Kristianstad University Dissertation and Theses). Retrieved from http://hkr.diva-portal.org/smash/get/diva2:230502/FULLTEXT01.pdf

Peterson, M. F., \& Fanimokun, A. (2008). National subcultural differences in use of social structures for four Nigerian ethnic groups. Paper Presented at the International Congress of Cross-Cultural Psychology, Bremen, Germany.

Schein, E. H. (2010). Organizational culture and leadership. San Francisco, CA: Wiley.

Schwartz, S. H. (1994). Are there universal aspects in the structure and contents of human values? Journal of Social Issues, 50(4), 19-45. http://dx.doi.org/10.1111/j.1540-4560.1994.tb01196.x

Tafjel, H. (1979). Individuals and groups in social psychology. British Journal of Social and Clinical Psychology, 18(2), 183-190. http://dx.doi.org/10.1111/j.2044-8260.1979.tb00324.x

Turner, J., \& Oakes, P. (1986). The significance of the social identity concept for social psychology with reference to individualism, interactionism and social influence. British Journal of Social Psychology, 25(3), 237-252. http://dx.doi.org/10.1111/j.2044-8309.1986.tb00732.x

Wyer, N. A. (2010). Selective self-categorization: Meaningful categorization and the in-group persuasion effect. The Journal of Social Psychology, 150(5). http://dx.doi.org/10.1080/00224540903365521

Yoo, B., Donthu, N., \& Lenartowicz, T. (2011). Measuring Hofstede's five dimensions of cultural values at the individual level: Development and validation of CVSCALE. Journal of International Consumer Marketing, 23(3-4), 193-210. http://dx.doi.org/10.5539/ibr.v7n12p143

Zúñiga, M. A., \& Torres, I. M. (2014). Influence of collectivist and individualist cultural orientation and regulatory construal fit on brand attitudes. Global Conference on Business and Finance Proceedings, 9(1), 91-93. Retrieved from http://search.proquest.com/docview/1503677819?accountid=34899

\section{Copyrights}

Copyright for this article is retained by the author(s), with first publication rights granted to the journal.

This is an open-access article distributed under the terms and conditions of the Creative Commons Attribution license (http://creativecommons.org/licenses/by/3.0/). 